\title{
Dimensions of Asthma and Its Treatment in the Kingdom of Saudi Arabia: Literature Review
}

\author{
Nashi Masnad Alreshidi* \\ Regional Nursing Administration in Hail Region, Saudi Arabia
}

Submission: May 02, 2017; Published: May 04, 2017

"Corresponding author: Nashi Masnad Alreshidi, RN, MSc, PhD, Continuing Nursing Education Director, Regional Nursing Administration in Hail Region, Saudi Arabia, Email: nmalreshidi@moh.gov.sa

\begin{abstract}
Background: More than 2 million people in the Kingdom of Saudi Arabia (KSA) complain of asthma, making it one of the most common chronic illnesses in the country and its prevalence is increasing.
\end{abstract}

Aim: this review aim to provide overview about the nature of asthma in the KSA, including its prevalence, risk factors, treatment guidelines and its adherence.

Method: Electronic searching was conducted on various data bases to search for these studies related to the aim. Search was confined for these studies published between 2000 and 2015.

Findings: Most of the previous research conducted in Saudi Arabia focused on establishing the prevalence of asthma. Children were the most affected developmental group from asthma in the KSA. Little was known about the outcomes of this illness among children in kingdom. Several barriers to patient adherence to asthma treatment were revealed including the nature of pharmacological therapy, lack of family support, and lack of patients' education by health care providers.

Conclusion: Patients with asthma in the KSA may benefit from better physiological and psychosocial performance when enrolling in health education sessions but evidence on this practice is still deficient.

\section{Introduction}

Asthma a chronic inflammatory disease usually begins in childhood and is characterized by recurrent attacks of breathlessness and wheezing, which vary in severity and frequency from one person to another. Asthma is induced by long term inflammation of the airway passages due to the hypersensitivity of the nerve endings in the airways causing epithelial fragility, goblet cell hyperplasia, enlarged submucosal mucus glands, increased airway smooth muscle mass, and wall thickening [1]. In the attack, the lining of the airway passages become swollen causing a reversible narrowing and obstruction in the airways which is clinically evidenced by wheezing, coughing, chest tightness, and shortness of breath [2].

In fact, the causes of asthma are not fully understood, but some potential contributory factors include environmental factors (i.e. respiratory virus infections, allergens, pollutants, medications or other irritants) [3]. Genetic factors (i.e. family history of asthma, racial and ethnic differences) [4], and are also implicated long-term uncontrolled inflammation, and early life exposures to irritant substances [5-7]. The mechanisms are multifaceted, so it is probable that both environmental factors and genes determine asthma vulnerability [8].

Saudi Arabia is one of the largest countries in the Middle East and has one of the largest oil reserves in the world [9]. More than 2 million people in Saudi complain of asthma attacks before being diagnosed as having asthma, which makes asthma one of the most common chronic illnesses and this prevalence is increasing $[10,11]$.

A number of studies, in Saudi Arabia, were conducted to investigate the reasons behind the significant prevalence of asthma among Saudi children. Several risk factors were found [12-14]. Being a Saudi national was found to be one of main risk factors associated with asthmatic symptoms. It seems Saudi children have specific genes significantly associated with asthma (5 single-nucleotide polymorphisms (SNPs) in the interleukin 17 (IL17) gene-rs17880588 (G/A) and rs17878530 (C/T) in IL17A and rs763780 (T/C), rs11465553 (T/C), and rs2397084 
(G/A) in IL17F-and a difference in the compared levels of the proteins (IL17A and IL17F) make them more susceptible to having asthma.

The treatment of asthma and maximum asthma control are impacted by patient knowledge, level of education, behavioural changes, adherence to managementregimes, physician experience and confidence, and the availability of health care services [15]. International and national evidence-based guidelines have been developed to assist both health care providers and patients to achieve optimal asthma control; their recommendations include enhancing corticosteroid prescription, minimizing $\beta 2$ agonist use, educating patients, and developing self-management skills. Children are treated individually according to their drug tolerance, compliance to the therapeutic regimens, and response to the ongoing asthma plan.

\section{Search strategy}

For the purpose of this review is to extensively search for related asthma studies in the KSA. the following databases were used for electronic searching for the period from 20002015: Cumulative Index of Nursing and Allied Health Literature (CINAHL), and the Database of the National Library of Medicine (MEDLINE) via (EBSCO); Ovid SP; The COCHRANE Library; ProQuest database; and Google Scholar. Terms used for searching was Asthma, Saudi Arabia/KSA, Treatment/Management, Prevalence, Risk factors, Guidelines.

Prevalence of Asthma Globally and In the KSA: Asthma is a worldwide significant health issue that needs various clinical and public health interventions. The estimated number of people suffering from asthma in the world is 300 million. The prevalence of asthma increases as communities adopt western lifestyles [12]. Both morbidity and mortality from asthma are high despite treatment that is effective for the majority of patients. Even in developed countries where patients have easy access to treatment, asthma is often under-recognised and under-treated, and sometimes fatal [15]. It is estimated that asthma accounts for one in every 250 deaths worldwide [12]. Many of these deaths are preventable and are due to suboptimal long-term medical care and delay in obtaining help during the final attack (SINA, 2012). The number of disability-adjusted life years (DALYs) lost due to asthma worldwide is estimated to be 15 million per year, which is similar to that for diabetes, liver cirrhosis, and mental disorders [16].

Although there is a varied picture of trends in asthma prevalence worldwide, there are still some areas where little is known about the disease or no data have been collected. These include parts of Asia, Africa and South America. In areas where asthma prevalence has only been reported in single crosssectional studies, there is also a scarcity of epidemiological data. These areas include Africa, Trinidad and Tobago, Dhakar, Albania, Greece, Nigeria, Israel, Beirut, United Arab Emirates, Kuwait, Palestine, Tamil Nadu, India and Qatar [17]. Although asthma prevelance in many parts of the world is increasing, it is evident that there is a gap in the literature on asthma is Asia and the Middle East as indicated by the limited number of reports with conflicting results considering that the available evidence has rarely used cohort designs.

A few studies have been conducted in the last 15 years to measure the prevalence of Asthma in children in Saudi Arabia $[18,19]$. A cross-sectional study was conducted in 2000 to explore the socio-clinical profile of asthmatic children and the impact of asthma symptoms on their life style in Al-Majmaah $(n=606$; age $=$ children $\leq 13$ years of age $)$ [15]. About $88 \%$ of the children presented with a combination of symptoms, a typical presentation of asthma in children. Of these, 51\% presented with cough, 78\% with dyspnea, and 91\% with wheezing. Another cross-sectional study aimed to investigate the changing prevalence of asthma in Jeddah, Riyadh, Hail and Gizan regions of KSA ( $n=2123$; age=8- 6 years old) using an internationally designed protocol in 1986 and 1995. The prevalence of asthma increased significantly from $8 \%$ in 1986 to $23 \%$ in 1995 $(\mathrm{P}<0.0001)$. However, due to the cross-sectional nature of the above two studies, the validity of the results could be impacted by the snap shot effect of these studies.

Another study with larger sample size was conducted to study the prevalence of asthma in school children ( $n=5663$ age $=6-16$ years) in the KSA. The combined data revealed varying prevalence of asthma with the highest $24 \%$ being in a coastal city bordering Yemen called Gizan ( $n=362)$ followed by Taif $23 \%$ $(n=594)$ and Hail $22 \%(n=507)$. The prevalence rate of asthma in other places was: AI-Qassim 16\% ( $\mathrm{n}=384)$, Abha 13\% ( $\mathrm{n}=485)$, Dammam 12\% ( $\mathrm{n}=889)$, Hofuf 14\% (n=923), Jeddah $12 \%$ ( $n=531)$ and Riyadh 10\% ( $n=988)$ (Al-Frayh \& Hasnain, 2007). A very recent study was conducted to study the prevalence of Allergic Disorders among Primary School-Aged Children in Madinah (6-8 year old; $n=6,139)$. The results showed a high prevalence of asthma in children between 6-8 years, around $23.6 \%$ of school children in Madinah have asthma. However, another study has reported the overall prevalence in the KSA as $10 \%[15]$.

Figures from Nahhas et al. [19] study showed that Saudi Arabia is considered one of the highest risk regions in the world for asthma. These findings were augmented in previous research $[20,21]$. The possible explanation for the increased prevalence of asthma in Saudi children could result from the increase of air pollutants caused by larger vehicles the number and existence of factories close to housing unit's respons to the remarkable increase in the Saudi populations.

\section{Risk Factors for Asthma in KSA}

In Saudi Arabia, some factors increase the risk of asthma development or trigger symptoms in people with asthma, including both internal and external environmental elements such as infections, air pollutants, inhaled allergens, weather 
changes, chemicals, living in disadvantaged areas, occupational hazards, drugs, smoking, levels of exercise, educational status, economic status, emotional stress and certain foods. Indoor factors (in the home, school, and work place) are most commonly cited, as most asthmatic children tend to spend more time indoors. Other factors that aggravate asthma include underdiagnosis, lack of education, and poor health facilities and choice of treatment, along with poor adherence to the therapeutic regimes.

\section{Diet}

Diet is a major source of allergen exposures for people diagnosed with asthma [22]. Food can trigger an asthma attack due to an allergic response to foods such as peanuts, sesame, fish, dairy products, and eggs. Some people become wheezy when they have food containing certain additives such as tartrazine and histamine food. These food sources, which are common in use in the western-world as well as in Saudi traditional foods may exacerbate the situation and accelerate decline into an asthmatic attack. Knowledge about asthma was viewed as the most effective means to helping people to exclude nutrients that aggravate asthma symptoms from this diet. Evidence established by good quality clinical trials in the KSA revealed that children with better understanding and adherence to asthma nutritional regimes have significantly fewer of asthmatic episodes.

\section{Obesity}

Obese children frequently experience severe or persistent asthma. Obesity in children can also alter lung volume leading to rapid and shallow breathing patterns. Obesity can also cause reduction of the peripheral airway diameter which leads to an increase in airway hyper responsiveness.

\section{Infection}

Infectious diseases impact on children's immune system development especially when children are exposed to viral, bacterial, or parasitic infection. Respiratory tract infection may lead to asthma. Infectious diseases from microbial agents may potentially aggravate the development of chronic asthma especially when it seems recurrent.

\section{Smoking}

Generally, tobacco smoke damages tiny hair-like projections in the airways (cilia) Smoking can also cause the lungs to produce excessive mucus which results in airway obstruction. In children, passive smoking, which is the most common, is a problematic issue that decreases the lung functionality and increases the symptoms of airway inflammation such as cough, wheezing, and increased mucous production. Belonging to a family with parents who smoke was also found to be another positive risk factor for having respiratory symptoms in general and asthma in particular. Al-Dawood [15] has studied risk factors for asthma by distributing a questionnaire to asthmatic children and asked some questions about smoking of parents. In this study, it was found that the smoking rate among parents of children without asthma was significantly lower than that of parents of asthmatic children. There is no obvious evidence about the rate of smoking among children in the KSA. However, many studies related the increase in the prevalence of asthma between children in KSA to the apparent smoking phenomenon between school children. For that reason, asthma education about the role of smoking in aggravating asthma can contribute to increasing the awareness of that risk factor and decrease the overall cigarette consumption between school children.

\section{Air pollution}

Outdoor air pollution is usually associated with increased hospitalisation or emergency department visits for people with asthma. It also increases asthma mortality. Environmental pollution stimulates asthma exacerbation, especially in big cities. It can increase the risk of an asthma attack and readmission to hospital. In the KSA, air pollution is a major risk factor leading to asthma due to the accumulation of dust particles in the air which often exceed the upper limit recognized by the World Health Organisation (WHO, 2013). Increasing the level of desertification is the main cause of asthma in the KSA in addition to the toxic gas emissions from cars and industrial premises. It is emphasised that the only way to eliminate the effect of environmental factors is by decreasing the exposure to these risks as much as possible through increasing the individual orientation about the patterns and nature of these risks.

\section{Changes in Weather}

A sudden change in outside temperature can trigger an asthma attack such as cold air, windy weather, poor air quality, and hot or humid days. Further to the previous facts, Saudi communities suffer from the fluctuation in weather which is a common trait of all gulf countries. Variation between day and night temperatures, sudden fluctuation in humidity, and differences in altitude (refers to the height above sea level), are the most common environmental factors associated with the development of asthma in the KSA. While it is not possible to modify the weather in the KSA it is possible to increase the likelihood of children's ability to modify their life style or change their personal habits (e.g. type of playing), strategies that family members can contribute to reducing the effect of the weather on their health status.

A study in the KSA was conducted to test the differences between the prevalence of allergic symptoms in children living in urban and rural areas of Saudi Arabia ( $n=1444$; age 12 years old children). Logistic regression analysis highlighted that "urban residence" was one of the main risk factors responsible for asthmatic symptoms [23]. One of the main causes of this finding can be the presence of Alternaria spores in urban areas, which is one of the main fungal spores that cause asthma. A clinical study was carried out in several regions in Saudi Arabia to test the role of airborne Alternaria spores in causing asthma. A 
significant positive relationship was found between the presence of Alternaria spores and having asthma. Alternaria spores constituted between $1.9 \%-9.6 \%$ of the total fungal air spore, and the maximum concentration exceeded $5 \times 102$ spores per $\mathrm{m} 3$ of air in Jeddah, followed by 4.9x102 spores per m3 in Al-Khobar [24].

\section{Exercise}

Exercise induced asthma occurs when the airways narrow as a result of exercise (Henneberger et al., 2002). Exercise-induced symptoms occur commonly when the inhaled air is cold or dry due to air changes during vigorous activities. Typical symptoms of asthma present, such as shortenss of breath, chest tightness, and cough. Children with asthma in the KSA are more likely to be absent from school and are less likely to participate in physical activity compared to their healthy counterparts [25]. Poor asthma management was also significantly associated with poor quality of life (QoL) scores. A strong negative correlation was found between QoL and the severity of asthma. As asthma severity increases, patients' QoL decreases. Exercise can be a trigger for children when their asthma is not under good control, however, this does not mean that children with asthma should avoid exercise. As long as their asthma is under control, exercise is recommended to keep their lungs and body shape in a good posture and enhance normal growth and development. When asthma is controlled well or effectively, exercise will strengthen respiratory muscles, improve the immune system and help to sustain a healthy body weight. Swimming is one of the best forms of exercise for children with asthma because it usually causes the least amount of chest tightness especially in the KSA there are a plenty of beaches and swimming facilities available.

\section{Stress}

Physiologic stress such as inflammation or contagious diseases can cause wheezing and more vigorous asthmatic signs. Psychological stressors such as anxiety can also result in shortness of breath and exaggerate asthma symptoms. On the other hand, stress can develop as a result of persistent wheezing and coughing which may contribute to further psychological stressors and depression [26].

\section{Illiteracy}

Other risk factors are also associated with a high prevalence of asthma among Saudi children such as illiteracy of the parents, having a child in a family with a low income, the use of coal and wood for heating, living in a mud or tent house, lack of electricity inside dwellings, and the presence of sheep [27]. In the KSA, the nature of this life may characterise the vast majority of people especially who live in the rural and Bedouin It is argued that many of the risk factors could be avoided by providing families and their children with sufficient knowledge about how to avoid the triggers that cause asthmatic symptoms. However, children illiterate of parents can be educated by both verbal and direct communication. Therefore, there is a need in Saudi Arabia for research that focuses on providing children with asthma with knowledge that they can use to promote their own health and prevent asthma attacks.

\section{Asthma Guidelines}

Asthma cannot be cured, however, symptoms can be prevented and controlled in most cases when early detection of the disease is established, therapy guidelines are adhered to, and levels of knowledge are improved (National Asthma Education and Prevention Programme, 2007). To improve care, international guidelines (such as Global Initiative for Asthma (GINA), Global Asthma Initiative, Australia National Asthma Treatment Guideline, Canadian Thoracic Society (CTS) Asthma Committee) and national guidelines (KSA guidelines, 2012) for asthma diagnosis and treatment have been developed and updated to help physicians and patients achieve treatment goals and objectives of asthma. This includes preventing chronic symptoms, minimizing morbidity and mortality rates, maintaining a normal children daily activity levels, and decreasing hospital admissions and emergency visits. In addition, they contribute to reducing exacerbations of that disease, maximising lung function levels, prescribing suitable drugs to minimize adverse effects, reducing patients' negative perceptions, and saving time and money.

Abundant studies indicate that the guidelines are not completely implemented by health care providers: two studies in KSA alone reflect this: the first conducted in the Emergency Department in King Fahd National Guard Hospital and the second in the National Guard Iskan Primary Care Centre [28]. Reasons for the lack of implementation of the guidelines and a poor compliance to specific aspects of the guidelines are identified; they include the under-diagnosis of asthma, patient perceptions of asthma and its management, inappropriate medication choice, and the type and quality of the health care facility which includes the qualifications of the professional employees, the presence of health education programmes, and the cost of treatment in the hospitals [28]. There is no evidence of using the Asthma Cycle of Care in Saudi Arabia. Rather, the action plan currently used does not match any established guideline.

\section{Asthma Control}

As noted, the assessment of asthma control has become pivotal in the management of asthma. However, several surveys in developed nations have shown that the majority of patients with asthma do not experience adequate asthma control [29]. Asthma control and the degree of severity of symptoms are related, however, they are different. Control is defined as sufficient disease treatment; while severity is concerned with the fundamental process of the disease [30]. Interestingly, some studies support the use of asthma control based on an asthma management approach rather than on severity [31]. Five symptoms, namely being awoken at night, limitations of daily activities, morning waking with symptoms, dyspnoea, and wheezing, as well as short $\beta 2$ acting agonist use and deficiency of 
lung function, are considered as the most important indications for control assessment in national guidelines in many countries (GINA, 2002; Saudi MoH, 2000; Australian National Asthma Council, 2004, [32]).

A Turkish study involving 239 children implemented the Asthma Insights and Reality (AIR) survey to estimate asthma control levels based on the GINA guideline classifications [33]. In this study just $1.3 \%$ of patients were found to have achieved an optimum control level, and around $75 \%$ and $90 \%$ of children and adults respectively were experiencing daytime symptoms. Inhaled corticosteroids (ICSs) have been recommended in persistent asthma regardless of the severity of symptoms (mild, moderate, and severe), but the success of asthma control is largely dependent on adherence to ICS daily use. Other selfmanagement activities, such as education, Peak Flow Meter (PFM) use, monitoring of medication, trigger avoidance, inhaler practice, and use of Asthma Action Plans (AAPs) are also mentioned as contributory factors for relieving asthma symptoms [34,35]. Therefore, adherence to the therapeutic regime is a main goal in any asthma action plan. That said; there is a clear relationship between asthma severity and asthma control. The underlying severity of asthma in a patient may be modified by changes in the environment and by the treatment strategies which are based on strong asthma evidence. Ultimately, the changes in these environmental and treatment factors may impact on children's symptoms and their ability to function. Asthma control reflects the combined effects of underlying disease severity, environmental exposures and the effectiveness of treatment [36].

A number of patient-related variables may influence asthma control. Laforest et al. [37] conducted a cross sectional study to identify factors associated with asthma. The study found several independent patient-related determinants of inadequate asthma control, including female gender, active smoking and overweight. Control also varied according to the type of asthma supervision. Patients treated exclusively by specialists were more likely to have their asthma well controlled compared to those who were treated by a General Practioner (GP) Patients who were dispensed combined long-acting beta- 2 agonist (LABA) and ICS therapy were also more likely to have their symptoms properly controlled, particularly at higher doses of these drugs. This good quality study controlled for the confounding variables, making the findings transferable to other settings. Assessment of both asthma control and severity can depend on one or more of the following factors: symptoms, changes in expiratory flow, and airway inflammation. Assessments of results vary depending on the methods used. As asthma is a chronic disease with varying severity and levels of control over time, it can be difficult to accurately assess it with one method at a particular point in time; therefore, the use of more than one method has been recommended in asthma control.

\section{Barriers to Adherence to Asthma Management Guidelines}

Studies have reported some barriers that may reduce patient adherence to asthma treatment in general and to treatment with ICS in particular. These barriers are related to the medication (corticosteroid), the patients and their families, and physicians and other health team workers [38-40], and income status [41]. Asthma has a measurable impact on how people assess their overall health status. The 2004-2005 National Health Survey in Australia showed that among people with asthma, 42\% rated their health as 'excellent' or 'very good,' compared to $58 \%$ of people without asthma. At the other end of the scale, $28 \%$ of people with asthma rated their health as 'poor' compared to only $14 \%$ of people without asthma (ACAM, 2007). Most of the impact of asthma is on physical functioning and on the ability to perform social roles, such as work or study.

Several barriers have been shown to reduce the availability, affordability, dissemination and efficacy of optimal asthma therapies. As well as the patient barriers identified (such as poor education, culture differences and low income), the lack of symptom-based guidelines and low public health priority have been recognized as barriers to reducing the burden of asthma. Regarding children, ongoing asthma assessment is evidently deficient in the most of health care systems. Lack of early detection of asthma among school children or lack of the assessment of risk factors may contribute to low level of awareness and thus higher incidences of asthma [42].

\section{Limitations of Asthma Research in the KSA}

Most of the previous research conducted in Saudi Arabia focused on establishing the prevalence of asthma [19] and also the risk factors that lead to high prevalence of asthma in Saudi Arabian children. Some researchers have tried to establish a cause and effect relationship between asthma and specific variables such as the presence of specific genes in Saudi children thought to be responsible for asthma, while others have studied the relationship between specific foods and triggering of respiratory symptoms. The aforementioned studies have mainly focused on the biomedical treatment and the physical health of the asthmatic patients without addressing other perspectives [43-45]. Studying the illness from biomedical angle only is not enough as the other dimensions of care such as the psychosocial perspective are equally important. There is a need to study the asthma and children from a wider perspective to ensure the quality of life of the children is improved while receiving the current therapeutic plan.

\section{Conclusion}

There have been a number of attempts to measure the prevalence of asthma and its impact in Saudi Arabia. However, the above studies did not unveil the outcomes of this illness among children in Saudi Arabia. The studies confirmed that asthma 
treatment is heavily reliant on health education as a source of disease prevention (primary-secondary-tertiary prevention approach). Children in the KSA may suffer from the disease more than those elsewhere because of the ecological, demographic characteristics, the prevalence of the asthma disorder, and the availability of medical and rehabilitation programmes [46]. School children may benefit from better physiological and psychosocial performance when enrolling in health education sessions that help to promote their quality of life and improve their performed daily activities. Further research is required to shed light onto the outcomes for school children and strategies that should be undertaken to improve their quality of life.

\section{References}

1. Bai TR, Knight DA (2005) Structural changes in the airways in asthma: observations and consequences. Clinical Sc 108(6): 463-477.

2. Http://Www.Who.Int/Respiratory/Asthma/Definition/En/

3. Wark PA, Gibson PG (2006) Asthma exacerbations: Pathogenesis. Thorax 61(1): 909-915.

4. Eder W, Ege MJ, Von Mutius E (2006) The Asthma Epidemic. The New England Journal of Medicine 355(21): 2226-2235.

5. Http://Www.Brit-Thoracic.Org.Uk/Home/About-Bts.Aspx

6. http://www.nationalasthma.org.au/uploads/content/22-NAC-FirstAid-for-Asthma-Chart-Kids-FINAL.pdf

7. Busse WW, Lemanske RF (2001) Asthma. The New England Journal of Medicine 344(5): 350-362.

8. Ober C (2005) Perspectives on the Past Decade of Asthma Genetics. J Allergy Clinical Immunol 116: 274-278.

9. Http://205.254.135.7/Countries/Country-Data.Cfm?Fips=SA

10. Al Frayh A, Shakoor Z, Elrab M, Hasnain S (2001) Increased Prevalence Of Asthma In Saudi Arabia. Annals of Allergy. Asthma and Immunology 86(3): 292-296.

11. Alamoudi OS (2006) Prevalence of Respiratory Diseases in Hospitalized Patients in Saudi Arabia: A 5 Years Study 1996-2000. Annals of Thoracic Medicine 1(2): 76 - 77.

12. Al-Ghamdi B, Mahfouz A, Abdelmoneim I, Khan M, Daffallah A (2008) Altitude and Bronchial Asthma in Southwestern Saudi Arabia. East Mediterr Health Journal 14(2): 17-23.

13. Bazzi M, Sultan M, Al Tassan N, Alanazi M, Al-Amri A, et al. (2011) 9 Interleukin 17A and F And Asthmain Saudi Arabia: Gene Polymorphisms and Protein Levels. Journal of Investigational Allergology and Clinical Immunology 21(7): 551.

14. Hijazi N, Abalkhail B, Seaton A (1998) Asthma and Respiratory Symptoms in Urban and Rural Saudi Arabia. European Respiratory Journal 12(1): 41-44.

15. Masoli M, Fabian D, Holt S, Beasley R; Global Initiative for Asthma (GINA) Program (2004) The Global Burden Of Asthma: Executive Summary Of The GINA Dissemination Committee Report. Allergy 59(5): 469-478.

16. Bousquet R, Goffe' B, Le Pichon X, De Capitani C, Chopin C, et al. (2005) Comment On Subduction Factory: 1. Theoretical Mineralogy, Densities, Seismic Wave Speeds And $\mathrm{H}_{2} \mathrm{O}$ Contents By Bradley R Hacker Geoffrey A Abers, And Simon M Peacock, J Geophys Res 110: B02206.

17. Anandan C, Nurmatov U, van Schayck OC, Sheikh A (2010) Is the prevalence of asthma declining? Systematic review of epidemiological studies. Allergy 65(2): 152-167.
18. Al-Ghamdy YS, Al-Haddad NS, Adelgadir MH, Qureshi NA, Saleh MA, et al. (2000) Socioclinical Profile of Children with Asthma in Al-Majmaah Health Province. Saudi Medical Journal 21(9): 847-851.

19. Nahhas M, Bhopal R, Anandan C, Elton R, Sheikh A (2012) Prevalence of Allergic Disorders among Primary School-Aged Children in Madinah, Saudi Arabia: Two-Stage Cross-Sectional Survey. Plos One 7(5): E36848.

20.Al-Dawood K (2001) Parental Smoking and the Risk of Respiratory Symptoms among Schoolboys in Al-Khobar City, Saudi Arabia. J Asthma 38(2): 149-154.

21. Alshehri MA, Abolfotouh MA, Sadeg A, Al Najjar YM, Asindi AA (2000) Screening For Asthma And Associated Risk Factors Among Urban Schoolboys In Abha City. Saudi Medical Journal 21(11): 1048-1053.

22. Http://Www.Ginasthma.Org/

23. Hijazi N, Abalkhail B, Seaton A (2000) Diet and Childhood Asthma in a Society in Transition: A Study in Urban and Rural Saudi Arabia. Thorax 55(9): 775-779.

24. Al-Frayh A, Hasnain S (2007) Prevalence of Bronchial Asthma in Children in Saudi Arabia. World Allergy Organization Journal 20(2): S167.

25. Mohangoo AD, De Koning HJ, Mangunkusumo RT, Raat H (2007) Health-Related Quality Of Life in Adolescents with Wheezing Attacks. Journal of Adolescent Health 41(5): 464-471.

26. Schmittdiel J, McMenamin SB, Halpin HA, Gillies RR, Bodenheimer T, et al. (2004) The Use of Patient and Physician Reminders for Preventive Services: Results from a National Study of Physician Organizations. Preventive Medicine 39(5): 1000-1006.

27. Alshehri MA, Abolfotouh MA, Sadeg A, Al Najjar YM, Asindi AA (2000) Screening For Asthma And Associated Risk Factors Among Urban Schoolboys In Abha City. Saudi Medical Journal 21(11): 1048-1053.

28. Dashash NA, Mukhtar SH (2003) Prescribing For Asthmatic Children in Primary Care. Saudi Medical Journal 24(5): 507-511.

29. Lai CK, De Guia TS, Kim YY, Kuo SH, Mukhopadhyay A, et al. (2003) Asthma Insight and Reality in Asian Pacific. J Allergy Clin Immunol 111(2): 263-268.

30. Carlton BG, Lucas DO, Ellis EF, Conboy-Ellis K, Shoheiber O (2005) The Status of Asthma Control And Asthma Prescribing Practices In The United States: Results Of A Large Prospective Asthma Control Survey Of Primary Care Practices. J Asthma 42(7): 529-535.

31. Yawn BP, Algatt-Bergstrom PJ, Yawn RA, Wollan P, Greco M, et al. (2000) An In School CD ROM Asthma Education Programme. Journal of School Health 70(4): 153-159.

32. National Heart Lung and Blood Institute, \& National Asthma Education and Prevention Programme (2007). EPR-3. Expert Panel Report 3: Guidelines For The Diagnosis And Management of Asthma.

33. Sekerel BE, Gemicioglu B, Soriano JB (2006) Asthma Insights and Reality in Turkey (AIRET) Study. Respir Med 100(10): 1850-1854.

34. Williams LK, Pladevall M, Xi H, Peterson EL, Joseph C, et al. (2004) Relationship between Adherence to Inhaled Corticosteroids and Poor Outcomes among Adults with Asthma. J Allergy Clin Immunol 114: 1288-1293.

35. Rabe KF, Vermeire PA, Soriano JB, Maier W (2000) Clinical Management of Asthma in 1999: The Asthma Insight and Reality in Europe (AIRE) Study. Eur Respir J 16: 802-1687.

36. Humbert M, Holgate S, Boulet LP (2007) Asthma Control Or Severity: That Is The Question. Allergy 62: 95-101.

37. Laforest L, Van Ganse E, Devouassoux G, Bousquet J, Chretin S, et al. (2006) Influence of Patients Characteristics And Disease Management On Asthma Control. J Allergy Clin Immunol 117: 1404-1410. 
38. Conn KM, Halterman JS, Fisher SG, Yoos HL, Chin NP (2005) Parental beliefs about medications and medication adherence amongurban children with asthma. Ambulatory Pediatrics 5(5): 306-310.

39. Coté J, Cartier A, Robichaud P, Boutin H, Malo JL, et al. (1997) Influence on Asthma Morbidity of asthma education programs based on selfmanagement plans following treatment optimization. Am J Respir Crit Care Med 155(1): 1509-1514.

40. Modi AC, Lim CS, Yu N, Geller D, Wagner MH, et al. (2006) A multimethod assessment of treatment adherence for children with cystic fibrosis. J Cyst Fibros 5(3): 177-185.

41. Annett RD, Aylward EH, Lapidus J, Bender BG, DuHamel T (2000) Neurocognitive Functioning In Children With Mild And Moderate Asthma In The Childhood Asthma Management Programme. Journal Of Allergy And Clinical Immunology 105(4): 717-724.

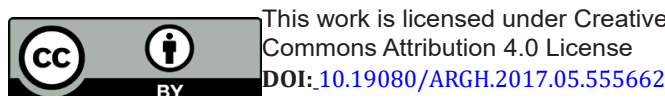

42. Suissa S, Ernst P, Kezouh A (2002) Regular use of inhaled corticosteroids and the long-term prevention of hospitalisation for asthma. Thorax 57(10): 880-884

43. Al-Dawood KM (2002) Schoolboys With Bronchial Asthma In Al-Khobar City, Saudi Arabia: Are They At Increased Risk Of School Absenteeism? Journal of Asthma 39(5): 413-420.

44. Farchi S, Forastiere F, Agabiti N, Corbo G, Pistelli R, et al. (2003) Dietary Factors Associated With Wheezing and Allergic Rhinitis in Children European Respiratory Journal 22(5): 772-780.

45. Rabe KF, Adachi M, Lai CK, Soriano JB, Vermeire PA, et al. (2004) Worldwide severity and control of asthma in children and adults: the global asthma insights and reality surveys. J Allergy Clin Immunol 114(1): 40-47.

46. Http://Www.Sinagroup.Org/

\section{Your next submission with JuniperPublishers will reach you the below assets}

- Quality Editorial service

- Swift Peer Review

- Reprints availability

- E-prints Service

- Manuscript Podcast for convenient understanding

- Global attainment for your research

- Manuscript accessibility in different formats

( Pdf, E-pub, Full Text, audio)

- Unceasing customer service

Track the below URL for one-step submission https://juniperpublishers.com/online-submission.php 